\title{
Modelos de produção e relações de trabalho no México do século xxI
}

\author{
Enrique de la Garza Toledo \\ Tradução do espanhol de Catalina Gonzalez Zambrano e Valter Luz
}

Introdução

Ao longo dos anos de 1990, na América Latina, no auge do modelo econômico neoliberal e da reestruturação produtiva das grandes empresas, o tema dos modelos de produção se estabeleceu e passou a dominar os estudos do trabalho. $\mathrm{O}$ interesse sobre esse tema acompanhou o desenvolvimento da teoria francesa da regulação, que em uma síntese analítica, feita por Freyssenet e Boyer (2000), refletiu sobre os resultados de muitos anos de pesquisa sobre a indústria automotiva mundial, revelando a multiplicação dos modelos de produção (Boyer e Saillard, 1996). Mas, se na indústria automotiva foram identificados oito modelos, no que diz respeito ao setor de serviços, fundamental para o Produto Interno Bruto da maioria dos países, houve um silêncio da teoria da regulação, embora se mencionasse que o conceito de modelo de produção não seria aplicável a tais serviços (Freyssenet, 2015). Assim, a partir do ponto máximo de abstração sobre modelos de produção na indústria automotiva, a teoria francesa, por um longo período, perdeu relevância. Foram os ingleses e os norte-americanos que retomaram o conceito para justamente aplicá-lo aos serviços, em conexão com as discussões atuais sobre trabalho não clássico (De la Garza, 2017).

No presente artigo, vamos analisar as virtudes e as deficiências do modelo exportador manufatureiro, estabelecido no México, na década de 1980, com ênfase nas condições e relações de trabalho (Calderón, 2003). A ênfase na manufatura se justifica pelo fato de esta ter sido apresentada como motor da economia devido às 
exportações, apesar de os serviços terem uma porcentagem maior de participação no PIB mexicano e de as exportações dos serviços serem marginais no novo modelo econômico. Pretendemos aprofundar as seguintes questões: Que partes da manufatura são consideradas como os verdadeiros motores da exportação? Qual é o modelo produtivo de melhor funcionamento? Qual tem sido o peso dos baixos salários nestes modelos de produção e, por sua vez, como se coloca o sindicalismo dominante - corporativista -, na articulação entre manufatura exportadora e baixas condições de trabalho? (De la Garza, 2014).

\section{0 modelo exportador manufatureiro}

A análise do neoliberalismo, assim como de muitos outros conceitos centrais nas ciências sociais, sempre foi cheia de ambiguidades e vazia de consenso quanto a seu significado. Em um trabalho escrito anteriormente, defendemos que esse conceito fosse definido como uma configuração (De la Garza, 1998), ou seja, uma rede não sistêmica que reúne o fundamento de uma visão do mundo e suas teorias específicas - homem racional e teoria neoclássica, por exemplo -; desregulamentação e abertura da economia, privatização e predominância das grandes corporações internacionais; e com políticas trabalhistas e sindicatos por parte do Estado, de apoio à flexibilização do trabalho, comumente acompanhada de precarização e afastamento dos sindicatos das decisões de política econômica e trabalhista.

Da mesma forma, os modelos de produção ${ }^{1}$ podem variar dentro da matriz que privilegia o livre mercado, de acordo com o estoque de produtos naturais, a provisão da mão de obra com determinadas características, o nível de rebaixamento dos sindicatos e a força do Estado para impor quadros de desregulamentação trabalhista e comercial. Destarte, a formação socioeconômica neoliberal no México, embora compartilhe traços gerais do neoliberalismo ao nível de modelos de produção, teve a manufatura exportadora como seu principal eixo, liderando nesse quesito os países do Cone Sul. O modelo de manufatura exportadora significa, em primeiro lugar, que, durante a vigência do modelo econômico neoliberal, a porcentagem das exportações representou um crescimento do PIB, de 5,2\%, entre 1960 e 1969, para 6,7\%, entre 1970 e 1981. A partir de 1982, com o neoliberalismo, o crescimento das exportações foi exponencial, atingindo 32\% entre 2010 e 2015 . Nesse modelo

1. Em vez de um modelo de produção com uma forte conotação funcionalista na versão regulatória, preferimos chamá-lo de "configuração sociotécnica de processos produtivos", que é uma rede não sistêmica de nível tecnológico, forma de organização do trabalho, perfil de força de trabalho, relacionamentos, culturas do trabalho e de gerenciamento (Neffa y De la Garza, coords, 2016) 
exportador, o peso das manufaturas no PIв foi alto. Em 1990, о PIB industrial/PIB total foi de $19,6 \%$, atingindo um pico em 2001, com 20,7\%.

Mas, se a importância da manufatura nas exportações começa a diminuir e no primeiro trimestre de 2010 se reduz para 17,5\%, em contrapartida, o seu volume nas exportações totais é impressionantemente alto, mantendo-se acima de $80 \%$ no século XXI. A elevada importância da manufatura na exportação, no entanto, não se repete no que diz respeito ao emprego. $\mathrm{O}$ emprego industrial, em relação à população economicamente ativa, atingiu seu pico com 24,9\% em 2002, 2003, 2004, mas caiu para $15 \%$ nos anos seguintes.

\section{QUADRO 1}

Importância da Indústria no PIB, nas Exportações e no Emprego

\begin{tabular}{|c|c|c|c|}
\hline AnO & PIB-M/PIB-T & Exp-M/Exp-T & Рто-M/Рто \\
\hline 1990 & 19,6 & 68,4 & - \\
\hline 2000 & 21,5 & 87,1 & 29,3 \\
\hline 2001 & 20,7 & 88,6 & 26 \\
\hline 2002 & 20,4 & 87,9 & 24,9 \\
\hline 2003 & 19,9 & 85,4 & 24,9 \\
\hline 2004 & 19,7 & 83,9 & 24,9 \\
\hline 2005 & 19,5 & 81,9 & 16,7 \\
\hline 2006 & 18,0 & 81 & 16,7 \\
\hline 2007 & 17,7 & 81,1 & 16,5 \\
\hline 2008 & 17,4 & 80,6 & 15,9 \\
\hline 2009 & 16,7 & 79,2 & 14,2 \\
\hline 2010 primer $T$ & 17,5 & 82,5 & 15,3 \\
\hline
\end{tabular}

Fonte: Inegi (2010) BIE. Aguascalientes: www.inegi.org.mx (consultado em 15/8/2010).

Configura-se um quadro em que o grande crescimento das exportações manufatureiras não traz consigo os demais setores da economia, nem gera muitos empregos. Também, nesse período de aumento das exportações, as importações cresceram, produzindo um déficit permanente na balança comercial.

No Gráfico 1, pode-se observar que, durante toda a era neoliberal, o crescimento anual do PIB a preços constantes foi fraco, com fortes quedas nas crises de 1997,2005 
GRÁFICO 1

Taxa de Crescimento Anual do PIB Real

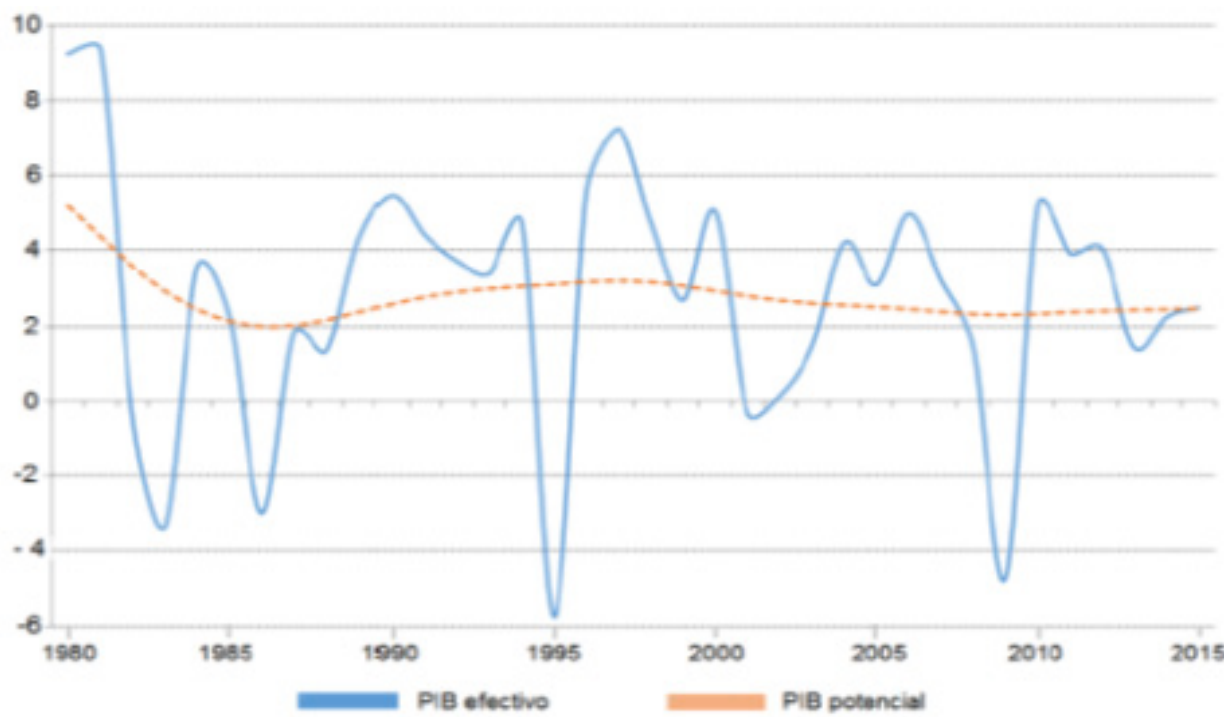

Fonte: Cepal, com base em cifras oficiais.

GRÁFICO 2

Crescimento Anual Médio do PIB e da Produtividade (1981-2011)

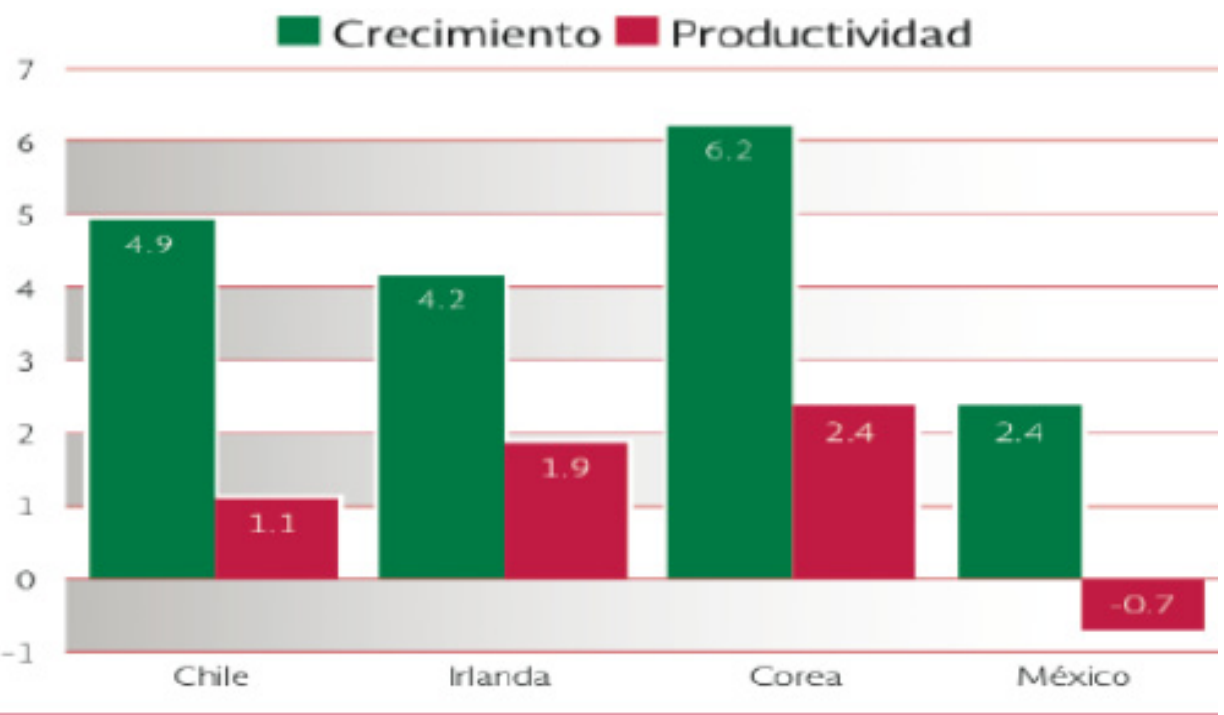

Fonte: Banco Mundial. 
GRÁFICO 3

Taxa de Crescimento do Volume da Produção da Manufatura, de sua Produtividade e Horas de Trabalho

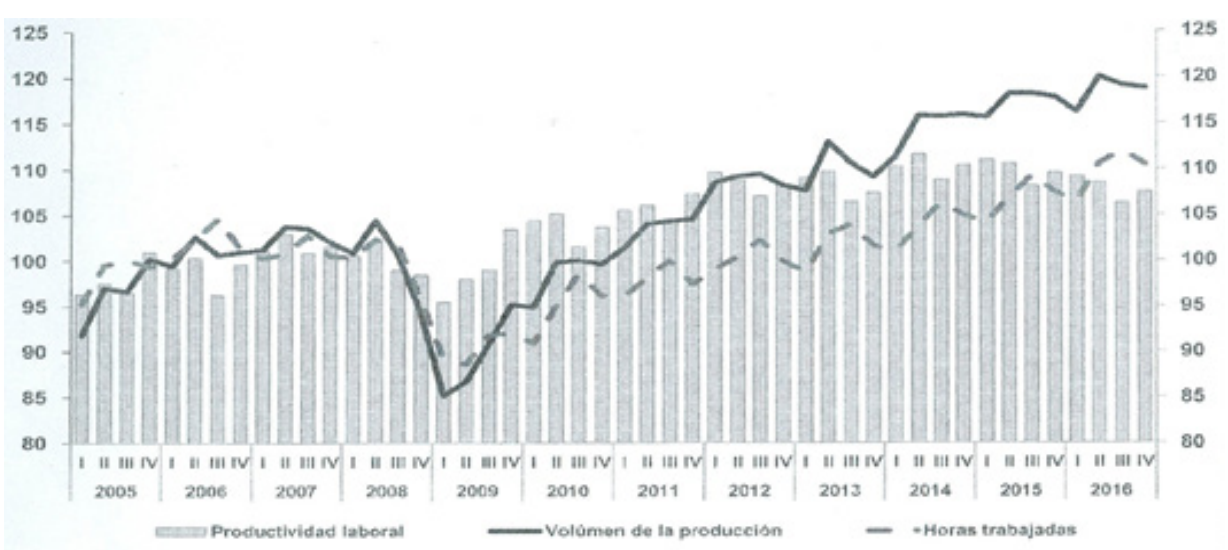

${ }^{*}$ Cifras revisadas a partir de 2016-I e preliminares a partir de 2016-III

Fonte: INEGI, Encuesta Mensual de la Industria Manufacturera (EMIM).

e 2008. Entre 1980 e 2016, o crescimento médio foi de 2,2\% ao ano. Isso significa que o apogeu exportador foi muito bom para as grandes corporações, especialmente multinacionais, mas insuficiente para arrastar a economia, como um todo, a taxas de crescimento aceitáveis (Robinson, 2013).

A comparação com outros países, como Chile, Irlanda e Coreia do Sul, entre 1981 e 2011, mostra um crescimento desprezível da economia mexicana, assim como uma produtividade negativa.

$\mathrm{Na}$ indústria manufatureira, conforme se nota no Gráfico 3, o volume de produção foi afetado pela crise de 2008-2009, mas depois cresceu de forma constante e a produtividade do trabalho na manufatura se recuperou após a crise; porém, a partir de 2012, estagnou. Como veremos, a competitividade necessária para o crescimento das exportações de manufaturas no exterior, principalmente nos Estados Unidos, não está provavelmente relacionada com a produtividade das fábricas no México.

O crescimento do emprego durante o modelo exportador de manufaturados não teve um grande impacto, especialmente se comparado ao período de substituição de importações. No período de crescimento do PIB, as taxas alcançaram cerca de 7\% durante a substituição de importações, sendo negativas na década de 1980, e muito baixas no século XXI. O mesmo pode ser dito sobre o crescimento da produtividade e do emprego. No caso específico do emprego, caiu para $0,97 \%$ na década de 1980 , subiu para $1,77 \%$ no início da década de 1990 e, novamente, declinou na década de 2000 , quando chegou a $0,61 \%$. 
QUADRO 2

Taxas de Crescimento Médias Anuais do PIB, da Produtividade e do Emprego

\begin{tabular}{lccccc}
\hline Conceito & $1950-1970$ & $1970-1982$ & $1983-1987$ & $1988-2003$ & $2000-2009$ \\
\hline PIB & 6,3 & 6,64 & $-0,7$ & 3,07 & 1,53 \\
Produtividade & 2,8 & 2,28 & 0,08 & 1,27 & 0,92 \\
Emprego & 2,12 & 4,26 & 0,97 & 1,77 & 0,61 \\
Salários & 6,62 & 2,48 & $-3,66$ & 2,34 & 1,4 \\
\hline
\end{tabular}

Fonte: Elaboração própria com base em Cuentas Nacionales, El Banco de México e Inegi (1950).

GRÁFICO 4

Porcentagem de Trabalhadores Assalariados na Manufatura em Relação à População Total Assalariada

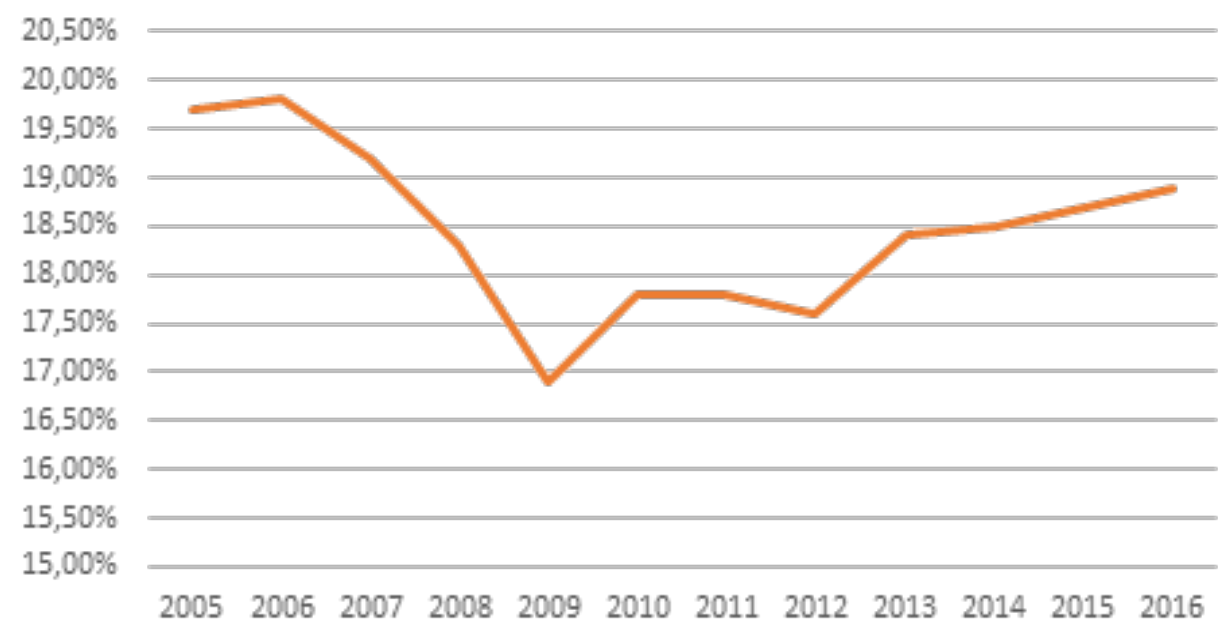

Fonte: Enoe.

A população assalariada na manufatura, em relação à população total assalariada, não é muito elevada e tende à estagnação, como pode ser observado no Gráfico 4.

Neste modelo exportador, o destaque foi a maquiladora (De la Garza, 2005). Como pode ser visto no Quadro 4, a importância da maquila nas exportações de manufaturas atingiu mais de 55\%, antes da grande crise do século xxi. Os dados dos anos mais recentes não são comparáveis, porque o governo mudou a definição de maquila, mas sua importância foi elevada em relação ao total das exportações mexicanas, atingindo mais de 48\%, no início do século XXI. Em outras palavras, o modelo exportador manufatureiro mexicano se expressa, principalmente, através da maquiladora de exportação, o que significa exportação de baixo valor agregado. 
Importância da Maquila na Economia Mexicana

\begin{tabular}{|c|c|c|c|c|c|}
\hline ANo & $\begin{array}{c}\text { Exportações da } \\
\text { maquila/exportações } \\
\text { de manufatura }\end{array}$ & $\begin{array}{c}\text { Exportações ma- } \\
\text { quila/total de } \\
\text { exportações }\end{array}$ & $\begin{array}{c}\text { Empregos na maquilal } \\
\text { empregos na } \\
\text { manufatura }\end{array}$ & $\begin{array}{l}\text { Valor agregado } \\
\text { maquila/PIB } \\
\text { manufatura }\end{array}$ & $\begin{array}{l}\text { Número de esta- } \\
\text { belecimentos } \\
\text { de maquila }\end{array}$ \\
\hline 1990 & $49 \%(1991)$ & 34,1 & 13,6 & 7,0 & 1.703 \\
\hline 2000 & 54,2 & 47,8 & 31,5 & 16,1 & 3.590 \\
\hline 2001 & 54,1 & 48,4 & 30,8 & 17,4 & 3.630 \\
\hline 2002 & 54,5 & 48,5 & 40,0 & 17,1 & 3.003 \\
\hline 2003 & 54,3 & 47,0 & 39,6 & 17,3 & 2.864 \\
\hline 2004 & 55,1 & 46,3 & 22,0 & 15,5 & 2.810 \\
\hline 2005 & 55,2 & 45,4 & 22,3 & 16,3 & 2.816 \\
\hline 2006 & $\mathrm{Nd}$ & $\mathrm{Nd}$ & 23,6 & 17,3 & 2.810 \\
\hline $2007^{*}$ & - & - & 38,9 & - & 5.145 \\
\hline $2008^{*}$ & 32,9 & 26,6 & 38,8 & - & 5.253 \\
\hline $2009^{*}$ & 29,1 & 23 & 25,4 & - & 5.259 \\
\hline $2010^{*}$ & 41,7 & 34,5 & 22,7 & - & 5.281 \\
\hline
\end{tabular}

*Câmbio de base de cálculo da maquila ampliada a outros programas de importação temporal de insumos (Inmex).

Fonte: Inegi (2010), BIE. Aguascalientes: www.inegi.com.mx (consultado em 21/8/2010).

Embora as exportações tenham aumentado, o mesmo não ocorreu na mesma medida com o emprego. A porcentagem de empregados na maquila em relação ao total de empregados apresenta uma tendência à queda; da mesma maneira, o valor agregado na maquila com relação ao valor agregado na manufatura é baixo, não superior a $17 \%$. Em contraste, os estabelecimentos de maquiladoras apresentaram um crescimento acelerado.

No que diz respeito ao comportamento dos salários, uma medida da deterioração é a porcentagem de trabalhadores que recebem uma renda inferior a três salários-mínimos. Considerando uma renda de cinco salários-mínimos como base para a sobrevivência, custo aproximado da cesta básica no México, esse grupo de trabalhadores se encontra abaixo da linha da pobreza. Essa porcentagem de trabalhadores aumentou de $54 \%$ da população total ocupada em 2007, para 62\%, em 2016. A mesma porcentagem de trabalhadores com benefícios estagnou desde 2013, bem como daqueles com contratos de trabalho permanentes. 
O que mais chama a atenção nesse modelo não é apenas o crescimento das exportações, mas a calamidade com relação aos salários. Os salários-mínimos reais seguem o comportamento mostrado no Gráfico 5. Entre 1980 e 2011, o salário-mínimo real caiu em $68,4 \%$, e os salários sob contrato - aqueles que são concedidos a cada ano aos trabalhadores que têm contratos coletivos e aos sindicalizados, que supõem, por sua vez, melhores condições do que as de outros trabalhadores - caíram em 50,5\%.

QUADRO 5

Variação Porcentual do Salário-minimo Real e do Salário sob Contrato

\begin{tabular}{ccc}
\hline Período & SalÁrio-mínimo Real & SAlário sob Contrato \\
\hline $1980-1990$ & $-50,69 \%$ & $-36,37 \%$ \\
$1990-2000$ & $-36,46 \%$ & $-25,45 \%$ \\
$2001-2006$ & $-2,28 \%$ & $-0,75 \%$ \\
$2007-2012$ & $0,02 \%$ & $-0,5 \%$ \\
$1980-2011$ & $-68,4 \%$ & $-50,5 \%$ \\
$1990-2012$ & $-31,4 \%$ & $-21,95 \%$ \\
\hline
\end{tabular}

Fonte: Anexo estatístico ao informe do governo de Peña Nieto.

GRÁFICO 5

Salário-minimo em Pesos de 2015 (229,1 pesos Equivalem a 11,5 Dólares Diários)

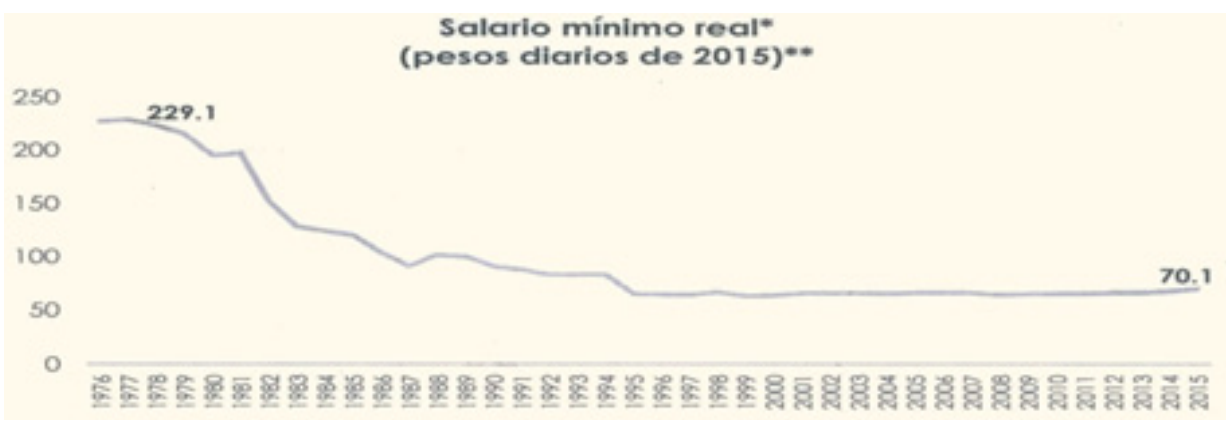

*A partir de $1^{\circ}$ de outubro de 2015, o Conselho de representantes da Conasami resolveu unificar as áreas geográficas do país com um mesmo salário mínimo: \$70,10 pesos diários. ${ }^{* *}$ Os dados do INPC 2012 correspondem a outubro. Fonte: Estimativas com base nos dados do Instituto Nacional de Estatística y Geografia (INEGI) e da Comisión Nacional de Salarios Mínimos. 
GRÁFICO 6*

Trajetória da Inflação e do Incremento do Salário sob Contrato

70

60

50

40

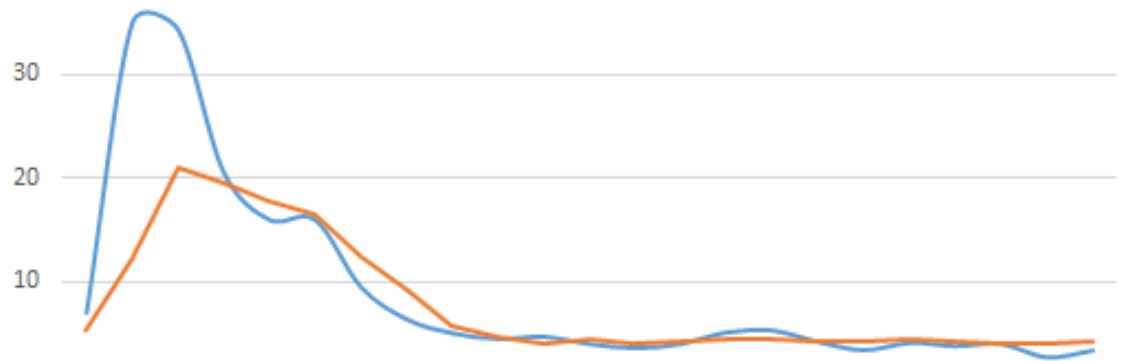

0

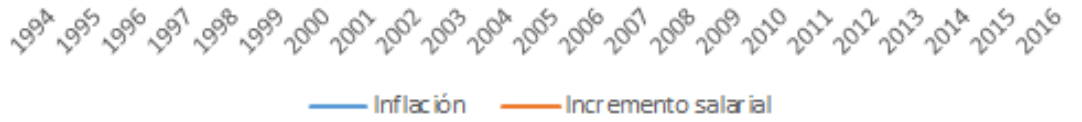

*O gráfico não deve ser interpretado como uma evolução do salário real contratual. Trata-se, porém, da comparação do crescimento em cada ano do salário contratual nominal em relação à inflação.

Fonte: Elaboração própria a partir do Anexo estatístico do IV informe do governo de Peña Nieto.

GRÁFICO 7

Indice da Produtividade Laboral e dos Custos Trabalhistas

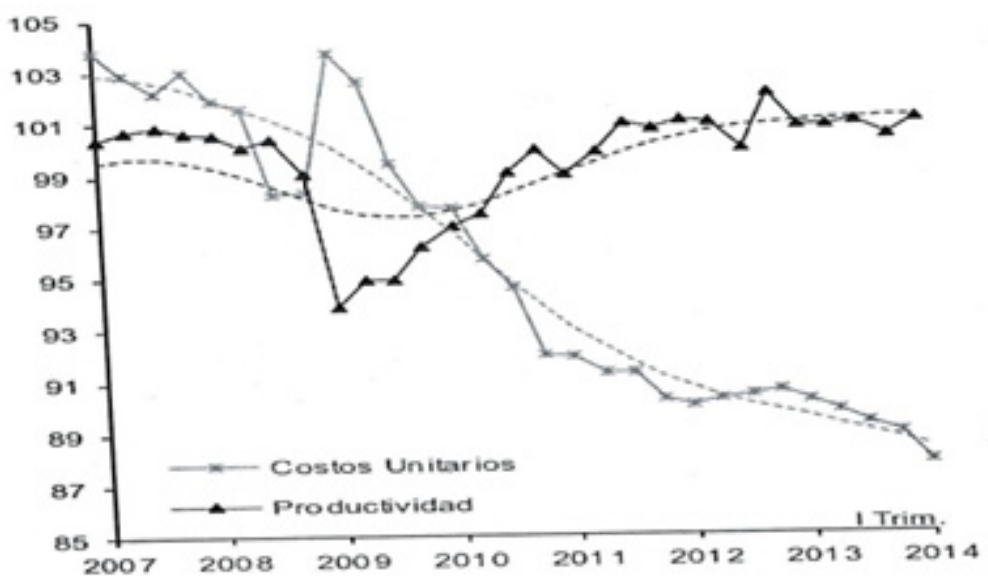

Fonte: Sistema de Cuentas Nacionales. 
Por fim, o Gráfico $6^{2}$ compara a inflação anual com o crescimento do salário real. A partir de 2002, o aumento salarial sob contrato anual ficou estabelecido com base na inflação esperada. A receita monetária elementar foi seguida de aumentos salariais iguais à inflação esperada para o ano seguinte. Tais inflações sofreram uma redução percentual, de tal modo que esse aumento no início quase coincidiu com a inflação do ano. Isso significou uma perda de dois pontos percentuais a cada ano, com respeito ao ano anterior, pois a inflação no século XXI teve uma tendência à queda. Ou seja, a queda salarial não se deveu apenas ao mercado, mas a uma política estatal de comum acordo com os grandes empresários que controlam as organizações empresariais mais importantes. Tudo isso ocorreu através do cinturão de transmissão da Comissão de salários-mínimos, supostamente tripartite, passando aos líderes sindicais e aos gerentes de empresas. Portanto, a debacle dos salários no México no atual modelo foi o produto de uma política premeditada que, como veremos, atraiu investimentos estrangeiros.

A queda dos salários não pode ser atribuída ao alinhamento dos salários de acordo com o crescimento da produtividade. Embora esse crescimento tenha sido medíocre, com uma tendência à estabilização, como se mostra no Gráfico 7 , os custos trabalhistas não acompanharam a produtividade, mas continuaram a diminuir de uma maneira desenfreada. Há evidências suficientes para afirmar que a debacle salarial no México tem sido uma política projetada pelos órgãos econômicos do Estado com vistas a atrair o investimento estrangeiro.

\section{Modelos produtivos na manufatura (configurações sociotécnicas)}

A maquiladora se constituiu na base principal do modelo exportador manufatureiro. Desde o início, no México, criou-se uma polêmica sobre a maquila como a via para o desenvolvimento do país. As maquiladoras começaram como uma indústria de montagem simples, com mão de obra pouco qualificada, baixa tecnologia, salários baixos, com contratos de proteção do empregador, com sindicatos controlados pela administração e ausentes dos locais de trabalho, com líderes e contratos desconhecidos para os trabalhadores. Em seguida, constituiu-se uma segunda geração com um elevado nível tecnológico, com novas formas de organização do trabalho, maior qualificação e melhores salários. Uma terceira geração seria uma maquiladora geradora de conhecimentos, não no sentido do conhecimento tácito, mas como "fábricas" de pesquisa e desenvolvimento. Em contraposição, argumentou-se que não havia significativamente, nem existe ainda, uma maquila de criação de conhecimentos. Este

2. A maneira de interpretar este gráfico não é em termos da trajetória do salário real, mas em termos de quanto aumentou a cada ano o salário nominal em relação à inflação. 
item entraria na maquiladora de serviços, ainda minoritária em todos os sentidos, frente a uma maquiladora eminentemente manufatureira. Nestes anos, a maioria dos pesquisadores da indústria maquiladora tenderam a criticar as três gerações, como a versão mexicana do upgrading de Gereffi. Nessas condições, vieram as novas fábricas de carros e caminhões, bem como o crescimento das fábricas de autopeças, embora estas últimas sejam principalmente maquiladoras (camadas 2 e 3). Há, na perspectiva governamental, uma substituição do setor motor do modelo econômico, passando da maquila para a indústria automotiva.

Em pesquisa anterior (De la Garza, 2006), com uma amostra representativa de maquilas, concluímos que a maioria não tinha tecnologias de ponta; que, no máximo, aplicavam de modo não sistêmico algumas formas novas de organização do trabalho; que o nível de flexibilidade e qualificação da força de trabalho era entre médio e baixo. As maquilas com tecnologia de ponta não representavam mais que $10 \%$ dos estabelecimentos, sem qualquer coerência entre tecnologia, organização, flexibilidade ou qualificação. Em contraste, as maquilas com organização fordista representavam a maioria (77\%); isso se viu refletido na geração de produtos de baixo valor agregado, com baixos salários dos trabalhadores e baixa produtividade (De la Garza, 2002). O índice de produtividade na maquila caiu de 100 em 1990 para 99,7 em 2004.

QUADRO 6

Configurações Produtivas nas Maquilas

\begin{tabular}{l|c}
\hline \multicolumn{1}{c|}{ PERFIL } & PorCENTAGEM \\
\hline $\begin{array}{l}\text { Organização fordista, tecnologia baixa ou média, flexibilidade baixa ou média e qualificação } \\
\text { de baixa a média }\end{array}$ & $47,2 \%$ \\
Organização fordista, tecnologia baixa ou média e qualificação alta & $7,5 \%$ \\
Organização fordista, tecnologia baixa ou média, flexibilidade alta e qualificação de baixa a média & $9,4 \%$ \\
Organização fordista, tecnologia baixa ou média, com flexibilidade e qualificação altas & $3,8 \%$ \\
Organização fordista, tecnologia alta, com flexibilidade e qualificação baixa ou média & $9,4 \%$ \\
Organização toyotista, com tecnologia, flexibilidade e qualificação baixa ou média & $17,0 \%$ \\
Organização toyotista, com tecnologia e flexibilidade baixa ou média e qualificação alta & $3,8 \%$ \\
Organização toyotista, com tecnologia alta, mas com flexibilidade e qualificação baixa ou média & $1,9 \%$ \\
\hline TotAL & $100,0 \%$ \\
\hline
\end{tabular}

Fonte: De la Garza (2005).

Na manufatura, em geral, a situação não é diferente. Esse setor quase não investe em pesquisa e desenvolvimento, e as tecnologias de ponta se concentram nas grandes empresas. No entanto, as novas formas de organização do trabalho têm se difundido amplamente. 
QUADRO 7

Câmbios na Organização do Trabalho em Manufatura

\begin{tabular}{|c|c|c|}
\hline & $\begin{array}{c}\text { CÂMBIOS NA ORGANIZAÇÃO } \\
\text { DO TRABALHO }\end{array}$ & $\begin{array}{c}\text { CÂMBIOS COMPLEXOS EM ORGANIZAÇÃO } \\
\text { DO TRABALHO (CEP E JIT) }\end{array}$ \\
\hline \multicolumn{3}{|l|}{1994} \\
\hline Grande & 64,1 & 17,7 \\
\hline Médio & 53,0 & 15,6 \\
\hline Pequeno & 37,1 & 15,5 \\
\hline \multicolumn{3}{|l|}{1998} \\
\hline Grande & 96 & 10,2 \\
\hline Médio & 89,6 & 12,8 \\
\hline Pequeno & 81,5 & 14,0 \\
\hline \multicolumn{3}{|l|}{2001} \\
\hline Grande & 95,4 & 19,0 \\
\hline Médio & 95,2 & 4,9 \\
\hline Pequeno & 82,1 & 12,6 \\
\hline \multicolumn{3}{|l|}{$2004^{*}$} \\
\hline Total & 22,9 & 8,45 \\
\hline Grande & 77,1 & - \\
\hline Médio & 72,0 & - \\
\hline Pequeno & 7,0 & - \\
\hline
\end{tabular}

Isso também se expressa na distribuição das categorias de trabalhadores por tamanho de estabelecimento, quando predominam os trabalhadores não qualificados em estabelecimentos grandes. Uma maneira diferente de estimar a qualificação da Enoe é apresentada nos resultados do Quadro 8.

\section{QUADRO 8}

Porcentagem de Operários Assalariados no Setor Formal, Segundo Qualificação com Respeito ao Total de Operários

\begin{tabular}{lccc}
\hline Qualificação & 2005 & 2010 & 2016 \\
Não Qualificados & $35,3 \%$ & $39,5 \%$ & $34,5 \%$ \\
Intermedí́rios & 45,2 & 39,9 & 45,6 \\
Qualificados & 19,5 & 20,6 & 19,9 \\
\hline & 100 & 100 & 100 \\
\hline
\end{tabular}

Fonte: Elaboração própria a partir da Enoe.

Ou seja, os assalariados especializados formais representam proporções muito baixas em relação aos trabalhadores assalariados formais não especializados. Quanto 
aos salários baixos, os operários qualificados, que ganhavam três ou menos salários-mínimos (abaixo do nível de subsistência), em 2005, representavam 40\% e, em 2016, eram 45\%. A grande maioria dos trabalhadores qualificados recebia até cinco salários-mínimos, o que estaria mais ou menos no nível de subsistência. Esses trabalhadores formais qualificados estariam empregados principalmente na manufatura em grandes e médias empresas (mais de trezentos trabalhadores).

QUADRO 9

Distribuição de Categorias de Trabalhadores por Tamanho do Estabelecimento para Manufatura - Não Maquiladora

\begin{tabular}{lccccc}
\hline & Total & Grande & Médio & Pequeno & Micro \\
\hline Total & 100 & 42,3 & 12,4 & 16,3 & 29,0 \\
\hline Diretores & 6,3 & 0,1 & 2,1 & 4,1 & 16,4 \\
Empregados & 21,9 & 22,7 & 22,2 & 22,3 & 20,3 \\
Operários especializados & 21,7 & 23,4 & 21,1 & 18,0 & 21,5 \\
Operários gerais & 49,9 & 53,8 & 54,6 & 55,6 & 41,8 \\
\hline
\end{tabular}

Fonte: Inegi (2004), Enestyc.

Além do que vimos, o modelo de manufatura do tipo maquilador não se caracteriza pelo estabelecimento de amplas cadeias de valor dentro do país. Uma vez que as multinacionais passaram a ter um papel central na maquila e na manufatura exportadora, as cadeias de valor, é claro, existem, mas como cadeias globais, onde os insumos ou componentes, principalmente estes, são estrangeiros. $\mathrm{O}$ mesmo pode ser dito de outros vínculos operativos em termos de cooperação entre fábricas, como pode ser visto no Quadro 9, onde os joint ventures, o outsourcing, as empresas integradoras, os clusters e o uso de submaquilas são escassos. É por isso que não se deve estranhar o pouco efeito multiplicador das manufaturas para o conjunto da economia, expresso no baixo incremento do PIB anual.

QUADRO 10

Vinculos Operativos entre o Estabelecimento na Manufatura e a Maquiladora

\begin{tabular}{lcc}
\hline \multicolumn{1}{c}{ Tipo de vínculo } & Porcentagem total & Porcentagem dos grandes \\
\hline Joint Ventures & 0,08 & 4,0 \\
Outsourcing & 0,65 & 14,7 \\
Empresas integradoras & 0,3 & 9,2 \\
Clusters & 0,04 & 1,8 \\
Uso de maquila & 3,5 & 31,9 \\
\hline
\end{tabular}

Fonte: Inegi (2005), Enestyc. 
GRÁFICO 8

Salário para Trabalhadores em Dólarespor Hora no Canadá, Estados Unidos e México no Terminal Automotivo e em Autopeças

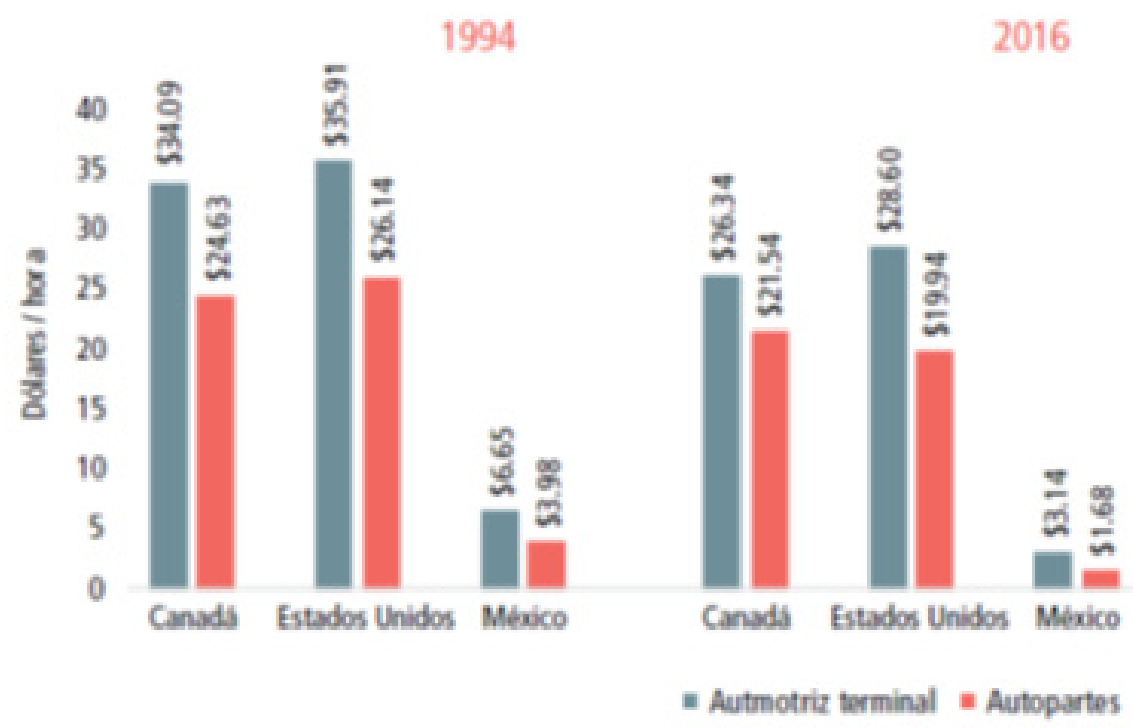

\footnotetext{
${ }^{a}$ Salários por hora estimados com base na equipe operacional e horas-trabalho para o México, para trabalhadores em postos não gerenciais nos Estados Unidos e o total de trabalhadores no Canadá.

Fonte: INEGI, U. S. Bureau of Labor Statistics e Statistics Canadá. Taxa de câmbio Banxico e CanadianForesc.
}

A nova esperança para o modelo exportador de manufatura é a nova Indústria Automotiva (IA) que foi instalada a partir do ano 2000. No entanto, esta IA precisa ser dividida em duas partes: uma é a montadora; e a outra, a produtora de autopeças. A primeira é de alta tecnologia e paga melhor do que a manufatura em geral, embora substancialmente menor do que nos Estados Unidos ou no Canadá. Atualmente, cada IA representa apenas 3,5\% do PIB, 19,8\% do PIB industrial e $8 \%$ do total das exportações. No emprego, é apenas $0,6 \%$ da PEA. Com relação aos salários, o setor de montagem paga melhor do que a média da manufatura, mas o número de trabalhadores é menor - 26 mil no IMSS -, com variação quanto às fábricas; as mais antigas e combativas em termos reivindicativos pagam melhor. No entanto, o setor de autopeças, onde se encontra a grande maioria dos trabalhadores do setor automotivo ( 850 mil), paga menos que a manufatura em geral, ou seja $133 \%$ menos do que as montadoras.

O principal problema é a falta de interesse das montadoras em desenvolver cadeias produtivas no México, o que amortece o caráter multiplicador do desenvolvimento nacional. Sessenta e cinco por cento das empresas de autopeças são estrangeiras já instaladas no país e não diferem, em geral, das maquiladoras, quer dizer que não são de primeira camada. 
GRÁFICO 9

Porcentagens que Representam os Salários e os Impostos em Valores Agregados da IA

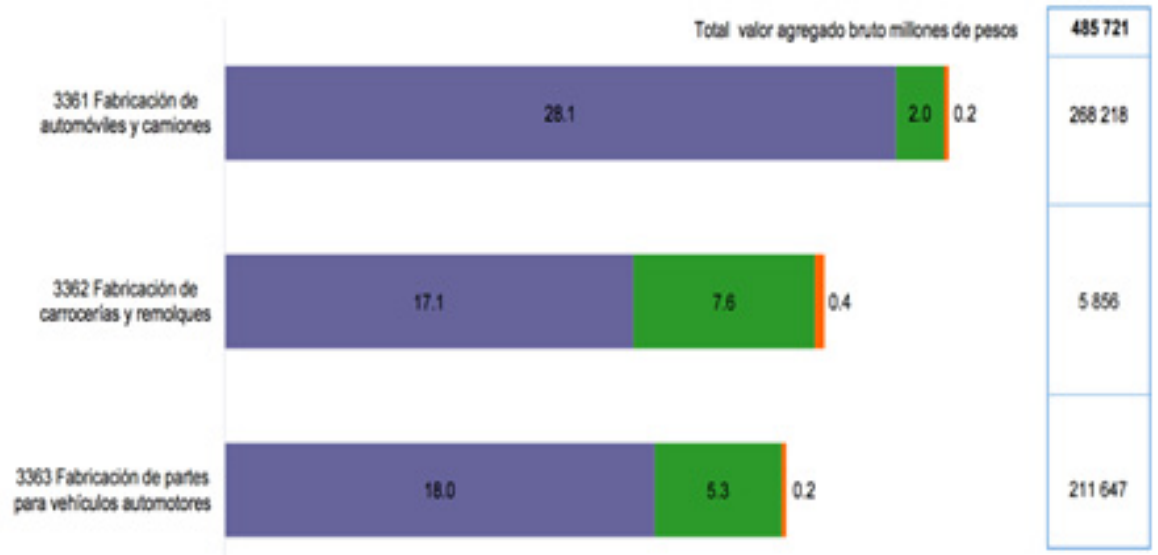

-Exoedenta bnto de operación IRemureracion de asalarados IImpuestes netos a la produción

Fonte: INEGI, Sistema de Cuerntas Nacionales de México. Cuentas de Bienes y Servicios 2003-2014. Ver Ruiz Durán (2017).

GRÁFICO 10

México: Cadeias para Trás e para Frente em LA, 2012

Fabricación de partes para vehiculos automotores

Fabricación de carroceria y remolques

Fabricación de automó viles ycamiones

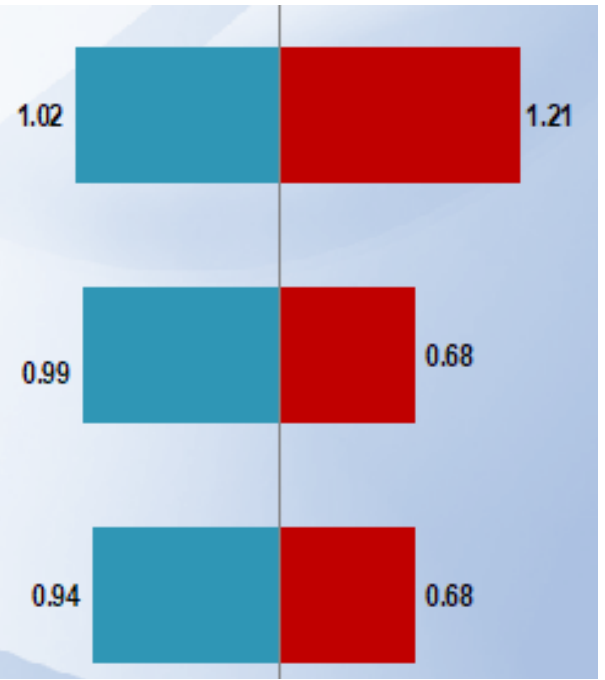

Fonte: Sem autor (2017)

As empresas automotivas diferem em valor agregado, sejam montadoras, sejam fábricas de carrocerias e reboques ou autopeças. Mas a porcentagem desse valor que toca os salários, na montagem, corresponde apenas a 2\% desse valor agregado; em autopeças, 5,3\%. De igual maneira, no pagamento de impostos, o valor agregado é quase nulo: $0,2 \%$ na montagem, $0,2 \%$ nas autopeças, devido às políticas explícitas dos 
governos federal e estadual para, praticamente, isentar essas empresas do pagamento de impostos para que possam instalar-se nas localidades.

O modelo exportador manufatureiro, portanto, agora baseado na indústria automotiva, não tem o efeito impulsionador necessário para o crescimento global da economia mexicana, ou do emprego. Assim, enfrenta de novo problemas de crescimento da produtividade; e, embora os salários sejam melhores na área da montagem, na comparação internacional, são mal pagos. Seja pela via da maquiladora ou pela via da indústria automotiva, fica claro que o modelo se baseia nos baixos salários.

\section{As relações de trabalho}

No México, o sindicalismo moderno foi inaugurado com a Revolução Mexicana de 1910-1917. Como resultado dessa revolução, os direitos trabalhistas básicos foram incorporados na Constituição de 1917 e depois no Código do trabalho. No entanto, o sindicalismo que se institucionalizou foi concebido como aliado do Estado da revolução mexicana, compondo o corporativismo sindical dos anos de 1930 com a incorporação das principais organizações de operários ao partido do governo (posteriormente seria o setor operário do PRI). Até o momento, a maior parte dos sindicatos e dos trabalhadores sindicalizados mantém relações corporativas com o governo. Esse corporativismo desempenhou um importante papel, agora muito diminuído, de levar eleitores e manifestantes aos atos públicos do PRI e do governo. Em contrapartida, suas lideranças ocuparam posições de representação na Câmara de Deputados, ou no Senado, bem como posições importantes nos governos. No entanto, com o crescimento da oposição a esse sistema político, a capacidade de atrair eleitores diminuiu, assim como as ocupações no poder público.

A outra função do corporativismo tem sido de apoiar as políticas governamentais, incluindo as econômicas e trabalhistas. Entre as políticas que permanecem até hoje estão as que afetam os aumentos salariais que partem da Comissão de salários-mínimos. Esta é a referência de aumento para que os líderes aceitem nas suas empresas. Assim sendo, possivelmente o vínculo corporativo mais importante na atualidade seja de ajudar a manter a paz laboral nas empresas, especialmente diante do desastre dos salários e da intensificação do trabalho, uma espécie de corporativismo não apenas de empresa, mas também de Estado.

As taxas de sindicalização no século XXI diminuíram tanto com respeito ao pessoal total subordinado e remunerado, quanto em relação à PEA ou à população total ocupada, como pode ser visto nos Quadros 11 a 13.

Embora as taxas de produção sejam superiores às taxas de sindicalização totais, na manufatura estas taxas têm diminuído. Uma explicação para isso é que a estrutura 
QUADRO 11

Taxa de Sindicalização Geral

\begin{tabular}{cccc}
\hline Ano & $\begin{array}{c}\text { Porcentagem de remunerados } \\
\text { e subordinados }\end{array}$ & $\begin{array}{c}\text { Porcentagem da população } \\
\text { economicamente ativa, PEA }\end{array}$ & $\begin{array}{c}\text { Porcentagem da população } \\
\text { total ocupada }\end{array}$ \\
\hline 2005 & 16,77 & 10,42 & 10,83 \\
2010 & 14,53 & 9,10 & 9,61 \\
2016 & 12,69 & 8,33 & 8,69 \\
\hline
\end{tabular}

Fonte: Elaboração própria a partir da Enoe.

QUADRO 12

Taxa de Sindicalização na Manufatura

\begin{tabular}{cccc}
\hline Ano & $\begin{array}{c}\text { Porcentagem de trabalhadores } \\
\text { subordinados e remunerados }\end{array}$ & $\begin{array}{c}\text { Porcentagem da população } \\
\text { economicamente ativa, PEA }\end{array}$ & $\begin{array}{c}\text { Porcentagem da população } \\
\text { total ocupada }\end{array}$ \\
\hline 2005 & $20,55 \%$ & $10,42 \%$ & $10,83 \%$ \\
2010 & 17,49 & 9,1 & 9,6 \\
2016 & 16,79 & 8,33 & 8,69 \\
\hline
\end{tabular}

Fonte: Enoe.

jurídica dificulta a sindicalização. Primeiro, porque apenas quem é dependente de um patrão e recebe uma remuneração salarial pode se sindicalizar. Isso ocorre porque existem remunerações não salariais, como o pagamento de honorários ou comissões, quando se estabelecem relações mercantis com o pagador. Os trabalhadores que entram na categoria não salarial, embora sejam subordinados e remunerados, não podem ser sindicalizados. Os trabalhadores independentes também não podem ser sindicalizados, nem quem trabalha por conta própria ou os trabalhadores da categoria não remunerados. As disposições anteriores reduzem o número de pessoas que podem ser sindicalizadas (Pacheco e De la Garza, 2011). Além disso, para formar um sindicato é necessário haver no mínimo vinte trabalhadores, o que deixa de fora os assalariados das micro e pequenas empresas de até vinte trabalhadores.

A outra dificuldade é processual, pois os procedimentos para registrar ou para mudar de sindicato são complicados. Isso deu origem ao fenômeno mexicano dos sindicatos e contratos de proteção patronal. Estes se originaram na década de 1930, aproveitando a corrupção das autoridades do trabalho e das lacunas na lei trabalhista. Registraram-se então sindicatos sem trabalhadores de tal forma que, quando uma empresa começava a contratar trabalhadores, descobria-se que já havia um sindicato. Por outro lado, a lei mexicana só permite firmar contrato com o sindicato majoritário. Os sindicatos de proteção não possuem vida sindical, os líderes assinam contratos mínimos às costas dos trabalhadores, e estes últimos nem sabem o que assinam. 
Outro fator inibidor das taxas de sindicalização é o imenso setor informal. Embora existam trabalhadores assalariados nesse setor, a informalidade da atividade comercial está ligada à falta de seguridade social, à falta de contrato e à impossibilidade de entrar no sindicato. As taxas de sindicalização medem apenas os trabalhadores que, segundo a lei, poderiam formar sindicatos. Pode-se ver que essas taxas crescem consideravelmente: $30 \%$ dos trabalhadores assalariados no setor formal estão sindicalizados e 19,5\% desses assalariados formais e os não formais.

No que diz respeito às limitações impostas à sindicalização, existe uma porcentagem expressiva de trabalhadores remunerados e dependentes que trabalham em condições informais ( $57 \%$ da população total ocupada); acrescenta-se que entre subordinados e remunerados assalariados existem $27 \%$ no setor informal (atividade comercial não registrada) e $73 \%$ no setor formal, além de pessoas que trabalham com percepções não salariais (comissões, honorários etc.), 40\% estão no setor informal e $60 \%$ no setor formal ${ }^{3}$.

QUADRO 13

Trabalhadores Subordinados e Remunerados Formais e Informais por Tipo de Unidade Econômica, México, 2016 (porcentagem)

\begin{tabular}{lcc}
\hline Tipo DE Unidade ECONÔMICA & Assalariados & COM PERCEPÇÕes NÃo SALARIAIS \\
\hline Setor informal & $27 \%$ & $40 \%$ \\
Fora do setor informal & $73 \%$ & $60 \%$ \\
\hline Total & $100 \%$ & $100 \%$ \\
\hline
\end{tabular}

Fonte: Estimativas próprias com base nos microdados da Encuesta Nacional de Ocupación, primeiro trimestre de 2016.

QUADRO 14

Porcentagem de Trabalhadores Subordinados e Remunerados com Percepções Não Salariais: Condiçôes de Trabalho

\begin{tabular}{lcc}
\hline Condição de trabalho & 2005 & 2016 \\
Sem contrato escrito & $81,3 \%$ & 80,7 \\
Até 5 salários-mínimos & 92,4 & 90,0 \\
\hline
\end{tabular}

Fonte: Elaboração própria a partir da Enoe.

Além disso, os subordinados e remunerados informais representam $40 \%$ do total. Esta é a nova informalidade que aumenta continuamente, considerando que não estão sujeitos a relações laborais, mas mercantis que, ao contrário da informalidade clássica, se encontram na maioria das vezes nos setores de comércio e serviços. Como

3. A definição pela OIT sobre qual trabalhador está em relação laboral informal tem duas conotações: os trabalhadores do setor (entendido como negócios não registrados) informal, além dos trabalhadores do setor formal que não possuem direitos trabalhistas. 
QUADRO 15

Conflitos Capital-Trabalho, de Jurisdição Federal

\begin{tabular}{lcccc}
\hline Ano & $\begin{array}{c}\text { Demandas individuais } \\
\text { Registradas }\end{array}$ & $\begin{array}{c}\text { Demandas coletivas } \\
\text { Registradas }\end{array}$ & Greves & $\begin{array}{c}\text { Trabalhadores Que } \\
\text { Aderiram Às Greves }\end{array}$ \\
\hline 2000 & 40,181 & 423 & 26 & 60,015 \\
2005 & 51,948 & 344 & 50 & 12,208 \\
2007 & 73,072 & 464 & 28 & 10,601 \\
2008 & 91,002 & 483 & 21 & 13,242 \\
2009 & 94,608 & 335 & 19 & 24,472 \\
2010 & 103,773 & 400 & 11 & 2,742 \\
2011 & 100,773 & 413 & 13 & 4,833 \\
2012 & 90,796 & 459 & 19 & 6,774 \\
2013 & 83,714 & 464 & 18 & 6,262 \\
2014 & 80,218 & 464 & 0 & 0 \\
2015 & 77,996 & 411 & 0 & 0 \\
$2016^{*}$ & 42,354 & 195 & 0 & 0 \\
\hline
\end{tabular}

*Janeiro-junho.

Fonte: Informe de trabalhadores da Junta Federal de Conciliacion y Arbitraje.

pode ser visto no Quadro 13, trata-se de trabalhadores muito pouco qualificados, com tendência à precariedade.

Por outro lado, em termos de assinatura de contratos, apenas em casos excepcionais em processo de desaparecimento, a lei permite contratos ramales, conhecidos também como contratos lei. A maioria desses contratos pertence apenas a um local de trabalho, e não a uma empresa, mesmo quando esta possui vários locais, independentemente de os sindicatos pertencerem à mesma federação ou confederação.

Mas o principal obstáculo para desencadear os conflitos entre trabalhadores e patrões são os sindicatos corporativos, garantidores da paz trabalhista, que usam truques para evitar que o conflito legal entre em erupção. Assim, como se observa no Quadro 15, as greves federais correspondem a empresas que têm estabelecimentos ou locais de trabalho em mais de um Estado. De 2014 até hoje não tem acontecido nenhuma dessas greves. Do mesmo modo, os conflitos coletivos - demandas apresentadas nos conselhos de conciliação de grupos de trabalhadores sem detonar a greve - têm se mantido estagnados desde 2000 em cerca de quatrocentos. Por outro lado, o número de conflitos individuais comumente exigidos pelo trabalhador, com a 
ajuda de escritórios de advocacia, sem passar pela união, permaneceu muito alto, com um máximo de 103.773 em 2010. Em outras palavras, o sindicalismo corporativo serve como regulador para o descontentamento dos trabalhadores, assumindo uma forma de demanda individual.

Considerando as greves totais (jurisdições federal e local) por períodos presidenciais, estas apresentam uma tendência à diminuição, não chegando a ser nulas porque algumas delas despontaram nos Estados.

QUADRO 16

Greves por Periodo Presidencial (Federais e Locais)

\begin{tabular}{lc}
\hline Período por Presidente & Greves \\
\hline Enrique Peña Nieto* & 19 \\
Felipe Calderón Hinojosa & 75 \\
Vicente Fox Quezada & 137 \\
Ernesto Zedillo & 213 \\
Carlos Salinas de Gortari & 505 \\
\hline
\end{tabular}

${ }^{*} 2013,2014,2015,2016$.

Fonte: Informe de Laborales de la Secretaria del Trabajo y Previsión Social.

\section{Conclusões}

Temos argumentado que no México existe uma articulação entre um modelo econômico baseado na exportação manufatureira e no investimento estrangeiro. Contudo, o elemento central desse modelo é a maquila de exportação e não a indústria de terminais automotivos.

Três aspectos são fundamentais nas configurações sociotécnicas dos processos produtivos próprios desse modelo: primeiro, as políticas econômicas do Estado mexicano (abertura econômica, desregulamentação e privatização), juntamente com os incentivos dessas políticas em favor da flexibilização do trabalho, a persistência do baixo salário e o predomínio dos sindicatos corporativos de controle dos trabalhadores. Porém, esses três sujeitos - funcionários do Estado, gerentes e líderes corporativos dos sindicatos - sublinham o fascínio do investimento produtivo em manter baixos salários e a paz laboral (Skañair, 2003). Por sua vez, os líderes sindicais se retroalimentam, demandando apoio institucional ao organismo estatal encarregado da regulação das relações de trabalho (conselhos de arbitragem e conciliação, de registro de associações, e juízes da área trabalhista). Essas instituições e, por ser necessária, a força pública asseguram o monopólio da representação por parte de tais líderes e impõem grandes dificuldades para sua substituição por sindicatos 
independentes. Em troca, os líderes apoiam a paz laboral e a aceitação formal das condições de trabalho desfavoráveis para os trabalhadores.

As administrações são beneficiadas com as condições laborais precárias impostas por essa grande aliança de forças antitrabalhistas, contribuindo com isso à sua reprodução ao condicionar as decisões de investimento para ter relações de trabalho adequadas. $\mathrm{O}$ governo acreditou que o crescimento seria alcançado à custa da precariedade dos trabalhadores, contudo isso não aconteceu. Pelo contrário, essa configuração de interesses articulados dos três grandes sujeitos exige uma precariedade crescente (Harvey, 2003; Stiglitz, 2003). A incógnita é quando essas condições de reprodução da classe operária serão minimizadas e aparecerá um movimento operário que desafie essa situação. Na história do México, nas décadas de 1940 a 1960, desencadeou-se o movimento operário nas grandes empresas, questionando as direções dos sindicatos corporativos. Poderia ser alcançada hoje, por analogia, tal situação? Estaria condicionada ao triunfo eleitoral da esquerda em 2018 ?

\section{Referências Bibliográficas}

Boyer, Robert \& SAILlard, Yves (eds.). (1996), La teoría de la regulación: estado del conocimiento. Buenos Aires, Universidad de Buenos Aires.

Calderón, Fernando (coord.). (2003), ¿Es sostenible la globalización en América Latina? Santiago do Chile, FCE.

De la Garza, Enrique. (1998), La formación socioeconómica neoliberal. Cidade do México, Plaza y Valdés.

. (2005), Modelos de producción en la maquila de exportación. Cidade do México, Plaza y Valdés.

. (2006), Reestructuración productiva, empresas y trabajadores en México. Cidade do México, Fondo de Cultura Económica

- (2014), La situación del trabajo en México. Cidade do México, Plaza y Valdés.

. (2017), “¿Qué es el trabajo no clásico?”. Ponenecia presentada en Santiago do Chile.

Freyssenet, Michel \& Boyer, Robert. (2000), Los modelos de producción. Buenos Aires, Lumen.

Harvey, David (2003), O novo imperialismo. São Paulo, Edições Loyola.

Neffa, J. C. \& De la Garza, Enrique (coords.). (2016), Trabajo y modelos de producción en América Latina. Buenos Aires, Clacso

Pacheco, Edith \& De la Garza, Enrique (coords.). (2011), Trabajos atipicos y precariedad del empleo. Cidade do México, El Colegio de México

Robinson, William. (2013), Una teoría sobre el capitalismo global. Cidade do México, Siglo XxI. 
Ruiz Durán, Clemente. (2017), Conferencia Impartida para La Fundación Ebert el 3 de abril, México, DF.

Sem AUtor. (2017), "El futuro de la industria automotriz en México". Apuntes para la Equidad, 1. SKLAIR, Leslie. (2003), Sociología del sistema global. Barcelos, Gedisa.

STiglitz, Joseph. (2003), El malestar en la globalización. Madri, Santillan Ediciones.

\section{Resumo}

Modelos de produção e relações de trabalho no México do século xxı

$\mathrm{O}$ artigo discute os problemas do modelo exportador manufatureiro, estabelecido no México, na década de 1980, enfatizando a questão do trabalho e dos sindicatos. A escolha do setor manufatureiro ocorre por ter sido ele apresentado como motor da economia devido às exportações, embora o setor de serviços tivesse uma participação maior no PIB mexicano. A proposta é analisar os segmentos industriais que são motores da exportação e o peso dos baixos salários e do sindicalismo dominante - corporativista nessa configuração econômica.

Palavras-chave: México; Modelos de produção; Relações de trabalho; Sindicato.

\section{Abstract}

Production models and labour relations in Mexico of the xxI century

The article discusses problems of the manufacturing exporting model, established in Mexico, in the 1980's, with emphasis on work relations and trade unions. The option for the manufacturing sector is because it has been presented as the engine of the economy, due to the exports, although the service sector has had a bigger participation in Mexican GDP. The intention is to analyse industrial segments that are the propellers of export, the strategy of low salaries and the dominant corporatist trade unionism in this economic configuration.

Keywords: Mexico; Production models; Labour relations; Trade unions.

Texto enviado em em 19/9/2017 e aprovado em 19/10/2017. Dor: 10.11606/0103-2070. ts.2018.138080.

ENRIQUE DE LA GARZA TOLEDO é professor pesquisador da pós-graduação da Uami na Cidade do México.Email: egt57@hotmail.com. http://spgwe.izt.uam.mx/pages/egt. 